\title{
Comparison between a submerged membrane bioreactor and a conventional activated sludge system on treating ammonia-bearing inorganic wastewater
}

\author{
Mengchun Gao, Min Yang*, Hongyan Li, Qingxiang Yang, Yu Zhang \\ State Key Laboratory of Environmental Aquatic Chemistry, Research Center for Eco-Environmental Sciences, \\ Chinese Academy of Sciences, Beijing 100085, China
}

Received 2 May 2003; received in revised form 25 November 2003; accepted 8 December 2003

\begin{abstract}
A submerged membrane bioreactor (SMBR) and a conventional activated sludge system (CAS) were compared in parallel over a period of 210 days on treating synthetic ammonia-bearing inorganic wastewater under similar conditions. Except for a short period of $\mathrm{pH}$ control failure, almost complete conversion of $\mathrm{NH}_{4}{ }^{-}-\mathrm{N}$ to $\mathrm{NO}_{3}{ }^{-}-\mathrm{N}$ was constantly achieved over an $\mathrm{NH}_{4}{ }^{+}-\mathrm{N}$ concentration range from 180 to $1300 \mathrm{mg} \mathrm{l}^{-1}$ at a hydraulic retention time (HRT) of $24 \mathrm{~h}$ in the SMBR, compared to an average conversion ratio of $95.0 \%$ in the CAS. Scanning electron micrographs (SEMs) demonstrated the accumulation of extracellular polymeric substances (EPSs) in the SMBR. Ubiquinone-8 (UQ-8), followed by UQ-10, UQ-7 and UQ-9, was the dominant ubiquinone in both the systems. The dominant menaquinone in the SMBR was menaquinone-6 (MK-6), while that in the CAS was MK-7, indicating that some differences existed between the two systems in terms of microbial community structure. Soluble microbial products (SMPs) tended to accumulate, and then biodegrade in SMBR.
\end{abstract}

(C) 2004 Elsevier B.V. All rights reserved.

Keywords: SMBR; CAS; Nitrification; SMP; EPS; Ubiquinone; Menaquinone

\section{Introduction}

Lithoautotrophic nitrification, the sequential transformation of $\mathrm{NH}_{4}{ }^{+}$via $\mathrm{NO}_{2}{ }^{-}$to $\mathrm{NO}_{3}{ }^{-}$, is typically catalyzed by two phylogenetically distinct groups of bacteria, i.e., the ammonia- and nitrite-oxidizing bacteria. Nitrifiers have been characterized by low growth rates and poor yields, and nitrification is generally

\footnotetext{
* Corresponding author. Tel.: +86-10-62923475; fax: +86-10-62923543.

E-mail address: yangmin@mail.rcees.ac.cn (M. Yang).
}

a rate-limiting step in a biological nitrogen removal process. Therefore, a major difficulty in biological nitrogen removal has been to maintain adequate levels of nitrifiers in the aeration tank. For this purpose, large aeration tanks have to be constructed to ensure a long sludge retention time (SRT) to retain nitrifiers in the conventional biological nitrogen removal process. SMBR, in which the absolute retention of all microorganisms could be realized through membrane interception (Kishino et al., 1995; Muller and Stouthamber, 1995), makes it possible to have adequate nitrifiers in the biological treatment system. 
SMBR has already been demonstrated to be very useful for nitrogen removal (Suwa et al., 1992; Chiemchaisri et al., 1992; Takao et al., 2001; Rosenberger et al., 2002). However, previous studies mainly focused on nitrogen removal performance of the SMBR. Little studies on nitrogen removal have been conducted by operating SMBR and CAS working in parallel under similar conditions, and no direct comparison of the two systems was done from the viewpoint of microbial characteristics.

The objective of this study was to clarify the differences between SMBR and CAS in terms of nitrification performance and microbial characteristics by operating the two systems in parallel over a long period (210 days). The two systems were only fed with synthetic ammonia-bearing inorganic wastewater to delete the factors unrelated with nitrification. An extensive comparison of the mixed liquor, sludge and effluent of both the systems was performed by investigating various chemical, biological and physical parameters.

\section{Results and discussion}

\subsection{Nitrification performance of SMBR and CAS}

Nitrification performance of the two systems is shown in Fig. 1A and B, respectively. With the in- crease of volumetric $\mathrm{NH}_{4}{ }^{+}-\mathrm{N}$ loading rate from 0.18 to $1.30 \mathrm{~kg} \mathrm{NH}_{4}{ }^{+}-\mathrm{N}_{\text {per }}{ }^{-3}$ per day by raising the influent $\mathrm{NH}_{4}{ }^{+}-\mathrm{N}$, almost complete conversion (>99\%) of $\mathrm{NH}_{4}{ }^{+}-\mathrm{N}$ to $\mathrm{NO}_{3}{ }^{-}-\mathrm{N}$ was attained in the SMBR except for a short period of $\mathrm{pH}$ control failure. The nitrification performance of the CAS, on the other hand, became deteriorated on hiking the influent $\mathrm{NH}_{4}{ }^{+}-\mathrm{N}$ concentration on days 95 and 136 , respectively. Especially in the later case, it took more than a month for the system to restore stable nitrification performance. Even under stable operation conditions, the conversion of $\mathrm{NH}_{4}{ }^{+}-\mathrm{N}$ to $\mathrm{NO}_{3}{ }^{-}-\mathrm{N}$ was between 95 and $97 \%$.

During the whole period of 210 days, the MLSS in the SMBR increased gradually from 2100 to $5500 \mathrm{mgl}^{-1}$, and the MLSS in the CAS increased from 2000 to $3700 \mathrm{mg} \mathrm{l}^{-1}$. It is believed that the high sludge concentration retained in the SMBR contributed to the stable nitrification performance of the system.

\subsection{Microbial aspects of the two systems}

Fig. 2 shows SEM photos of sludge from the two systems at different times. Rod- and oval-shaped bacteria and characteristic clusters of nitrifying bacteria could be distinctly identified from photos on day 40 . There was no apparent difference in morphology be-

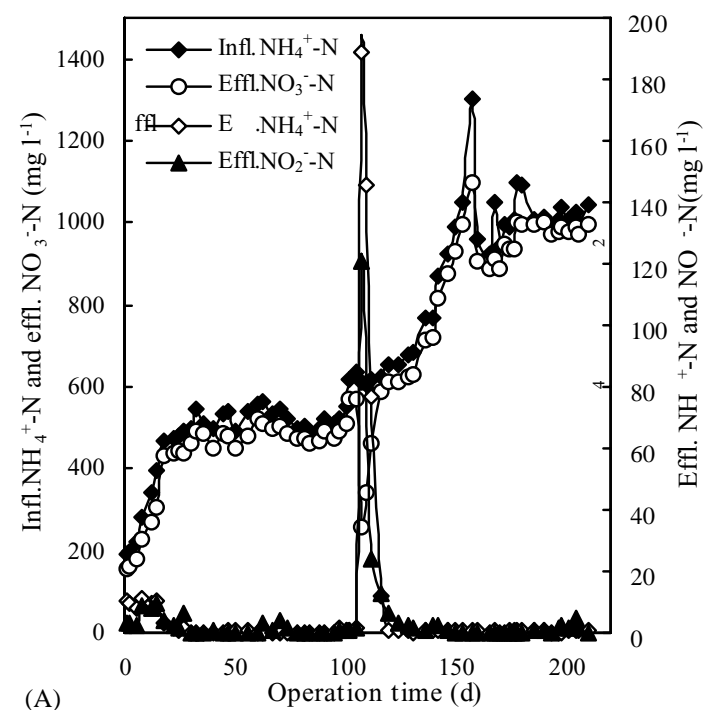

Fig. 1. Variation of nitrogen compounds over the operation time. (A) SMBR and (B) CAS. 

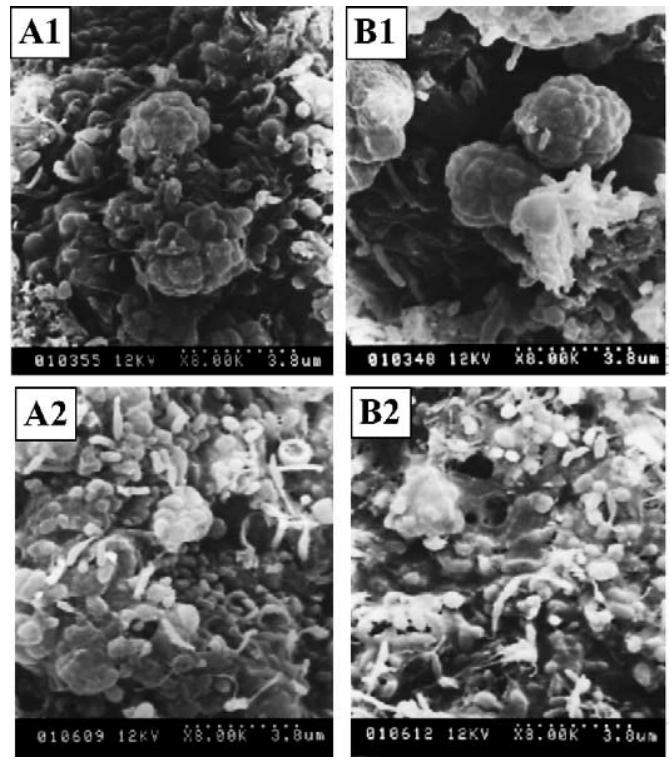

Fig. 2. Scanning electron micrograph indicating the spatial distribution of EPS and cell clusters over operation time in SMBR and CAS. (A1) The 40th day in the CAS; (A2) the 103rd day in the CAS; (B1) the 40th day in the SMBR; and (B2) the 103rd day in the SMBR

tween the two systems. However, with the prolongation of operation, microbes were gradually covered by EPS in the SMBR, and it was difficult to identify the microbial morphology clearly on day 103. Morphology of biomass in the CAS, on the other hand, was still clearly observed on day 103 . EPS has been considered to be one of the main reasons for membrane fouling (Hoddson et al., 1993; Nagaoka et al., 1996). So, it is important to purge sludge from the SMBR to prevent the accumulation of EPS.

The number of ammonia-oxidizing bacteria, nitrite-oxidizing bacteria and heterotrophic bacteria were determined by the most probable number (MPN) method as shown in Table 1 . The number of nitrifiers and heterotrophic bacteria in the two systems increased with the prolongation of operation time. It is interesting that a small amount of heterotrophic bacteria existed in both the systems although only inorganic wastewater was fed. It is estimated that the heterotrophic bacteria were responsible for the decomposition of dead cells and EPS.

\subsection{SMP of the two systems}

Fig. 3 shows variations of SMP in terms of total organic carbon (TOC) in supernatant liquor and the effluent of the two systems. Gradual increase of TOC in the supernatant was observed in both the systems in the first 120 days. Then, the TOC in the SMBR supernatant began to decrease while that in the CAS system remained almost constant. The decrease of TOC in the SMBR supernatant was possibly caused by biodegradation. The interception ability of membrane made it possible to retain SMP degradation bacteria in the system. The TOC in the SMBR supernatant began to be lower than that in the CAS supernatant from day 170 due to biodegradation of SMP.

\subsection{Microbial chemotaxonomy of two systems by microbial respiratory quinones}

The microbial community structures of the two systems were qualitatively analyzed on day 180 by microbial respiratory quinones (Gao et al., 2003). The dominant ubiquione was UQ-8 followed by UQ-10, UQ-7 and UQ-9 in both the systems. According to previous reports (Hiraishi, 1988), UQ-8 may represent Comamonas sp., certain members of Pseudomonas sp. and Alcaligenes sp., and UQ-10 was

Table 1

Variation of nitrifiers and heterotrophic bacteria in mixed liquors of SMBR and CAS

\begin{tabular}{|c|c|c|c|c|}
\hline \multirow[t]{2}{*}{ Number of days } & \multicolumn{2}{|c|}{ SMBR (1081 $1^{-1}$ mixed liquor) } & \multicolumn{2}{|c|}{ CAS ( $1081^{-1}$ mixed liquor) } \\
\hline & Nitrifiers $^{\mathrm{a}}$ & Heterotrophic bacteria & Nitrifiers $^{\mathrm{a}}$ & Heterotrophic bacteria \\
\hline 50 & 4.3 & 0.00026 & 0.91 & 0.00016 \\
\hline 90 & 13.47 & 0.00038 & 2.65 & 0.00021 \\
\hline 110 & 17.36 & 0.00043 & 3.92 & 0.00028 \\
\hline 150 & 24.23 & 0.000467 & 8.33 & 0.00031 \\
\hline 170 & 26.80 & 0.000545 & 9.87 & 0.00033 \\
\hline
\end{tabular}

\footnotetext{
${ }^{\text {a }}$ Data represent the sum of ammonia- and nitrite-oxidizing bacteria.
} 


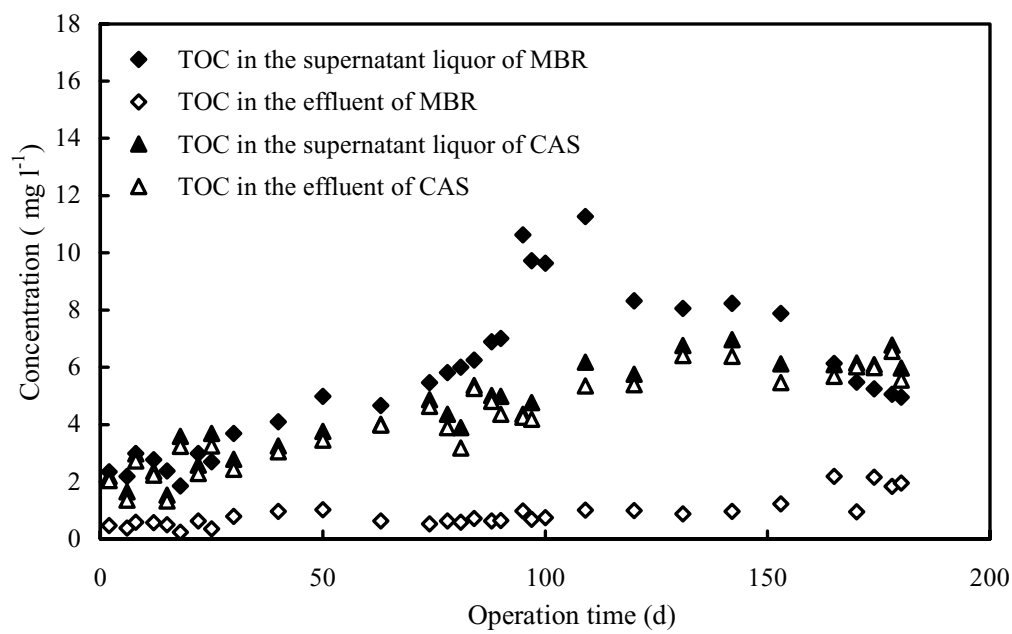

Fig. 3. Comparison of TOC in the supernatant liquor and the effluent between SMBR and CAS.

reported to be present in Protomonas sp. and Paracoccus $\mathrm{sp}$. The dominant menaquinone in the SMBR was MK-6 followed by MK-7, MK-8, MK- $8\left(\mathrm{H}_{2}\right)$, MK-9( $\left.\mathrm{H}_{2}\right)$, MK-9, MK-10 and MK-7 $\left(\mathrm{H}_{2}\right)$. The dominant menaquinone in the CAS, however, was MK-7 followed by MK-8( $\left.\mathrm{H}_{2}\right)$, MK-6, MK-8, MK-9, MK-9 $\left(\mathrm{H}_{2}\right)$ and MK-7 $\left(\mathrm{H}_{2}\right)$. Flavobacterium sp. and Cytophaga sp. contain MK-6 as a major quinone component, and MK-7 is often found in Flavobacterium sp., Cytophaga sp. Bacillus sp. and Staphylococcus sp. These results demonstrated that the two systems only had some minor differences in terms of microbial community structure. The meaning of the minor differences in microbial community to nitrification performance, however, requires further studies.

\subsection{Physical characteristics of sludge from the two systems}

Physical characteristics of sludge from the two systems were compared on day 135. For SMBR, particles in the size range of $50-200 \mu \mathrm{m}$ in diameter were about $72 \%$ in volume, and about $20 \%$ particles had a diameter of less than $50 \mu \mathrm{m}$. On the other hand, in the CAS system, $58 \%$ particles were in the size range of 50-200 $\mu \mathrm{m}$, and $23 \%$ particles had a diameter larger than $200 \mu \mathrm{m}$. The smaller particle size in SMBR was mainly due to violent current turbulence that aeration produced under the membrane module (Liu, 2002). The sludge index (SVI) for the SMBR was determined as $70 \pm 10 \mathrm{mlg}^{-1}$, while the SVI for the CAS was only $50 \pm 15 \mathrm{ml} \mathrm{g}^{-1}$.

\section{Conclusions}

The SMBR, which contained larger numbers of nitrifiers, was more effective and stable than the CAS in treating synthetic ammonia-bearing inorganic wastewater. SMP tended to accumulate, and then biodegraded in the SMBR. Periodical purging of sludge from SMBR is necessary to prevent the accumulation of EPS, which may cause the fouling of membrane. For both the systems, UQ-8, followed by UQ-10, UQ-7 and UQ-9, was the dominant ubiquinone. The dominant menaquinones, however, were different in the two systems, indicating that some differences in terms of microbial community structure existed between the two systems. Sludge particle size in SMBR was smaller than that in CAS.

\section{Acknowledgements}

Funding for this research was provided by the National Natural Science Foundation of China (Grants 
50238050), and State Hi-Tech Research and Development Project of the Ministry of Science and Technology, China (Grants 2002AA601310).

\section{References}

Chiemchaisri, C., Wong, Y.K., Urase, T., Yamamoto, K., 1992. Organic stabilization and nitrogen removal in membrane separation bioreactor for domestic wastewater treatment. Water Sci. Technol. 25 (10), 231-240.

Gao, M.-C., Yang, M., Hu, J., Shao, B., Zhang, H.-F., Li, H-Y., 2003. Identification of ubiquinones and menaquinones in activated sludge by liquid chromatography-atmospheric press chemical ionization mass spectrometry. J. Chromatogr. A 1007, 31-37.

Hiraishi, A., 1988. Respiratory quinone profiles as tools for identifying different bacterial populations in activated sludge. J. Gen. Appl. Microbiol. 34, 39-56.

Hoddson, P.H., Leslie, G.L., Schneider, R.P., Fane, A.G., Fell, C.J.D., Marshall, K.C., 1993. Cake resistance and solute rejection in bacterial microfiltration. The role of the extracellular matrix. J. Membr. Sci. 79, 35-53.
Kishino, H., Ishida, H., Iwabu, H., Nakano, I., 1995. Domestic wastewater reuse using a submerged membrane bioreactor. Desalination 106, 115-119.

Liu R., 2002. Microbial metabolic characteristics and membrane fouling control in a submerged membrane bioreactor. $\mathrm{PhD}$ thesis, Department of Environment and Engineering, Tsinghua University, Beijing, China.

Muller, E.B., Stouthamber, A.H., 1995. Aerobic domestic wastewater treatment in a plot plant with complete sludge retention by crossflow filtration. Water Res. 29 (4), 1179-1189.

Nagaoka, H., Ueda, S., Miya, A., 1996. Influence of bacteria extracellular polymers on membrane separation activated sludge process. Water Sci. Technol. 34 (9), 165-172.

Rosenberger, S., Krüger, U., Witzig, R., Manz, U., Szewzyk, M., Kraume, M., 2002. Preformance of a bioreactor with submerged membranes for aerobic treatment of municipal wastewater. Water Res. 36, 413-420.

Suwa, Y., Suzuki, T., Toyohara, H., Yamagishi, T., Urushingawa, Y., 1992. Single-stage, single-sludge nitrogen removal by activated sludge process with cross-flow filtration. Water Res. 26 (9), 1149-1157.

Takao, Y., Leite, J., Ueda, S., Yamaguchi, F., Suwa, Y., 2001. Simulaneous removal of phenol and ammonia by an activated sludge process with cross-flow filtration. Water Res. 35 (13), 3089-3096. 